\title{
Selective Heating of Pd-Modified Ordered Mesoporous Carbon CMK-3 by Microwave Irradiation
}

\author{
Satoshi Inagaki, ${ }^{1,2}$ Kenzo Onodera, ${ }^{1}$ Kensaku Tani, ${ }^{1}$ and Yoshihiro Kubota ${ }^{1}$ \\ ${ }^{1}$ Division of Materials Science and Chemical Engineering, Yokohama National University, \\ 79-5 Tokiwadai, Hodogaya-ku, Yokohama 240-8501 \\ ${ }^{2}$ Interdisciplinary Research Center, Yokohama National University, 79-5 Tokiwadai, Hodogaya-ku, Yokohama 240-8501 \\ Received May 31, 2011; E-mail: sinagaki@ynu.ac.jp
}

\begin{abstract}
Various microwave-heated heterogeneous catalytic reactions can be accelerated by choice of the catalyst supports and solvents. In this work, heterogeneous Pd catalysts supported on ordered mesoporous carbon CMK-3 and related catalysts were prepared. In the presence of these catalysts, the effect of microwave heating on Pd-catalyzed SuzukiMiyaura coupling as a probe reaction was investigated. The CMK-3 worked efficiently as a "carbon nanoflask" under microwave irradiation, especially in nonpolar solvents such as toluene and $o$-xylene with a lower ratio of dielectric constant $\left(\varepsilon^{\prime}\right)$ to dielectric loss $\left(\varepsilon^{\prime \prime}\right)(=\tan \delta)$.
\end{abstract}

Porous carbon materials are useful and indispensable in scientific and industrial applications. They are widely used as catalyst supports for many important catalytic processes, as sorbents for separation processes, and as electrode materials for batteries and capacitors. In particular, Pd-modified activated carbon $(\mathrm{Pd} / \mathrm{AC})$ has been already applied as an industrial heterogeneous catalyst in hydrogenation, hydrogenolysis, hydrocracking, and hydrodechlorination. ${ }^{1}$ Moreover, SuzukiMiyaura coupling, which is widely used in the organic synthesis of biaryl compounds, has been catalyzed by homogeneous Pd complexes ${ }^{2,3}$ as well as heterogeneous Pd/AC. ${ }^{4-14}$

The advantage of using heterogeneous catalysts is that they can be removed simply by filtration at the end of the reaction. As the product is uncontaminated with Pd metal or any other ligands and allows the catalyst to be recycled for other reactions, various kinds of heterogeneous $\mathrm{Pd}$ catalysts, such as $\mathrm{Pd} / \mathrm{AC},{ }^{4-15} \mathrm{Pd} / \mathrm{Al}_{2} \mathrm{O}_{3},{ }^{16} \mathrm{Pd} / \mathrm{USY}$ zeolite, ${ }^{17,18}$ Pd-containing perovskites, ${ }^{19}$ and Pd-immobilized hydrotalcite, ${ }^{20}$ have been used for the coupling reactions. Among the Pd-catalysts, $\mathrm{Pd} / \mathrm{AC}$ has been found to act as an efficient and inexpensive alternative to usual homogeneous catalysts, due to ligandless reaction ${ }^{4,5}$ and less leaching of $\mathrm{Pd}^{6-8}$ avoiding the abovementioned deterioration of the chemical products and a loss of expensive $\mathrm{Pd}$ metal and ligands. It is noteworthy that the catalytic activity of $\mathrm{Pd}(\mathrm{II}) / \mathrm{AC}$ is comparable to that of $\mathrm{Pd}(0)$ / $\mathrm{AC}$ in the coupling reaction of aryl bromide in the absence of $\mathrm{PPh}_{3}{ }^{4}$ This finding means that reductive pretreatment of $\mathrm{Pd}(\mathrm{II})$ to $\mathrm{Pd}(0)$ is not necessary when using $\mathrm{Pd} / \mathrm{AC}$ as a catalyst in the coupling reaction; the elucidation of mechanisms of coupling reactions over $\mathrm{Pd} / \mathrm{AC}$ is of great interest. Although many researchers have tried to understand such a reaction mechanism in a variety of reaction conditions, ${ }^{5-15}$ the elucidation of the truth of the matter is still an important issue.

Microwave irradiation promotes various organic chemical transformations, ${ }^{21-23}$ in particular, Pd-catalyzed coupling ${ }^{24-39}$ and other transition-metal-catalyzed coupling reactions. ${ }^{40,41}$
Since the first report of microwave-promoted $\left[\mathrm{Pd}\left(\mathrm{PPh}_{3}\right)_{4}\right]$ catalyzed coupling by Larhed and Hallberg, ${ }^{25}$ various microwave-assisted coupling reactions have been performed by using homogeneous $\mathrm{Pd}^{26-34}$ as well as heterogeneous catalysts, such as $\mathrm{Pd}$-doped $\mathrm{KF} / \mathrm{Al}_{2} \mathrm{O}_{3},{ }^{35,36} \mathrm{Pd} / \mathrm{AC},{ }^{37}$ polyurea microencapsulated $\mathrm{Pd}\left(\mathrm{Pd} \mathrm{EnCat}^{\mathrm{TM}}\right),{ }^{38}$ and $\mathrm{Pd} / \mathrm{SBA}-15$ mesoporous silica. ${ }^{39}$ Although Leadbeater and co-workers ${ }^{28}$ mistakenly reported transition-metal-free Suzuki-Miyaura coupling reactions with microwave irradiation, they have carefully done a reassessment of their previous methodology ${ }^{28}$ and found that Pd contaminants down to a level of $50 \mathrm{ppb}$ present in commercially available $\mathrm{Na}_{2} \mathrm{CO}_{3}$ used in their previous work $^{28}$ catalyze the coupling reaction with microwave irradiation. ${ }^{29}$ The acceleration effect of microwave irradiation on Pd-catalyzed Suzuki-Miyaura coupling reactions can be seen in a practical scene: $:^{30-34}$ for instance, the microwave-assisted coupling reaction of aryl chloride with phenylboronic acid in $N, N^{\prime}$ dimethylformamide (DMF)/water gave a high yield of $85 \%$ for $15 \mathrm{~min}$, whereas the same coupling reaction with conventional oil bath heating showed a low yield of $31 \%$ for $2 \mathrm{~h}^{29}$ On the other hand, in the coupling reactions of more active compounds such as aryl bromide or iodide, the product yield under microwave heating was similar to that under oil bath heating, indicating that the acceleration of Pd-catalyzed coupling reaction by microwave heating is not always observed, especially when the intrinsic reactivity is too high.

It is generally agreed upon that in many cases the observed enhancements in microwave-assisted reactions are in fact the results of purely thermal/kinetic effects, which are a consequence of the high temperatures that can rapidly be attained when irradiating polar materials or reaction mixtures under closed vessel conditions in a microwave field. Although some researchers have suggested controversial nonthermal microwave effects including a proposed direct interaction of the electric field with specific molecules in the reaction medium that is not related to macroscopic temperature, ${ }^{42}$ microwave- 
promoted chemistry is based on the efficient heating of materials by microwave dielectric heating. The heating characteristics of particular materials under microwave irradiation conditions are dependent on the dielectric properties. ${ }^{43}$ The ability of a specific material to convert electromagnetic energy into heat at a given frequency and temperature is determined by the loss factor, $\tan \delta$. This loss factor is expressed as the quotient $\tan \delta=\varepsilon^{\prime \prime} / \varepsilon^{\prime}$, where $\varepsilon^{\prime \prime}$ is dielectric loss, which is indicative of the efficiency with which electromagnetic radiation is converted into heat, and $\varepsilon^{\prime}$ is the dielectric constant describing the ability of molecules to be polarized by the electric field. A reaction medium with a high $\tan \delta$ value is required for efficient absorption and consequently for rapid heating. In general, solvents can be classified as high $(\tan \delta>0.5)$, medium $(0.1<\tan \delta<0.5)$, and low microwave absorbing $(\tan \delta<0.1)$ : for instance, $\tan \delta$ values of ethylene glycol, water and toluene at $2.45 \mathrm{GHz}$ and $20^{\circ} \mathrm{C}$ are 1.350 , 0.123 , and 0.040 , respectively. ${ }^{44}$ Since polar solvents with high $\tan \delta$ values show rapid and efficient heating by microwave irradiation, microwave-assisted Pd-catalyzed coupling reactions have often been attempted in a polar medium such as poly(ethylene glycol) $)^{26}$ or water. ${ }^{24,27,37}$

As solid materials are also efficiently heated by microwave irradiation, microwave heating of heterogeneous catalyst can realize a rapid and efficient catalytic reaction by selective heating of catalyst or catalyst support solids. Wada and coworkers ${ }^{45}$ have observed nonequilibrium local heating occurring in dimethyl sulfoxide (DMSO) in the proximity of Co particles under microwave irradiation by real-time in situ Raman spectroscopy. They also demonstrated the rate-enhancement in the catalytic dehalogenation of the $\mathrm{C}\left(\mathrm{sp}^{3}\right)-\mathrm{Cl}$ bond of 2-chloroethylbenzene and 4-phenylbutyl chloride caused by nonequilibrium local heating of the surface of $\mathrm{Co}$ and/or $\mathrm{Fe}$ catalyst particles under microwave irradiation. ${ }^{45}$ This finding provides a strong basis for realizing the construction of a highly efficient reaction field on the surface of heterogeneous catalyst solid by microwave irradiation.

Since carboneous materials also are efficiently heated by microwave irradiation, they are good candidates for catalyst support in microwave-assisted heterogeneous catalytic reactions. In particular, microporous activated carbon (AC) has been utilized for microwave-promoted reactions as follows: $\mathrm{Pd} / \mathrm{AC}$ for Suzuki-Miyaura coupling reaction ${ }^{37}$ or hydrogenation, ${ }^{46-48}$ and $\mathrm{Pt} / \mathrm{AC}$ for dechlorination. ${ }^{49}$

We have used the ordered mesoporous carbon CMK-3 ${ }^{50,51}$ instead of activated carbon as a catalyst support. In this study, we have attempted microwave-assisted Suzuki-Miyaura coupling catalyzed by $\mathrm{Pd} / \mathrm{CMK}-3$ or several related catalysts with careful observation of the reaction temperatures, and investigated the microwave dielectric heating effects of reactants, solvents, and catalyst supports on the temperature of the reaction mixture and the product yield.

\section{Experimental}

Preparation of Pd/Porous Carbon Catalysts. Ordered mesoporous carbon, CMK-3, and activated carbon, YP50F (Kuraray Chemical), were used as a catalyst support. CMK-3 was prepared as follows: ${ }^{50,51}$ hexagonally ordered mesoporous silica SBA-15 was hydrothermally synthesized from a mixture of $\mathrm{Si}(\mathrm{OEt})_{4}$, nonionic surfactant (Pluronic P123, $\left.(\mathrm{EO})_{20}(\mathrm{PO})_{70}(\mathrm{EO})_{20}\right)$ in aqueous $\mathrm{HCl}$ solution and then calcined at $550{ }^{\circ} \mathrm{C}$. A solution of $1.25 \mathrm{~g}$ of sucrose, $1.25 \mathrm{~g}$ of distilled water, and $0.14 \mathrm{~g}$ of concentrated $\mathrm{H}_{2} \mathrm{SO}_{4}$ was added dropwise to $1.0 \mathrm{~g}$ of calcined SBA-15. The moist SBA-15 was manually stirred for a few minutes and then dried at $100^{\circ} \mathrm{C}$ for $3 \mathrm{~h}$ followed by heating at $160^{\circ} \mathrm{C}$ for $4 \mathrm{~h}$ to give a brownish powder. Then, a solution of $0.8 \mathrm{~g}$ of sucrose, $1.6 \mathrm{~g}$ of distilled water, and $0.09 \mathrm{~g}$ of concentrated $\mathrm{H}_{2} \mathrm{SO}_{4}$ was added dropwise to the brownish powder, followed by repeating the drying and heating procedure once more. Carbonization of the obtained powder was carried out at $950{ }^{\circ} \mathrm{C}$ in vacuo $(<200 \mathrm{~Pa})$ and then silica etching of the carbonized products (ca. $1.4 \mathrm{~g}$ ) was performed by using $5.0 \mathrm{~g}$ of $10 \mathrm{wt} \% \mathrm{HF}$ solution to give CMK-3 (ca. $0.5 \mathrm{~g}$ ).

Impregnations of $\mathrm{Pd}(1.0 \mathrm{wt} \%)$ on CMK-3 and activated carbon were performed by evaporation-to-dryness. An appropriate amount of bis(acetylacetonato)palladium, [Pd(acac $\left.)_{2}\right]$, was dissolved in acetone to prepare $1.3 \mathrm{mM}$ Pd solution. Next, $500 \mathrm{mg}$ of porous carbon was added and the whole suspension was stirred at room temperature for $4 \mathrm{~h}$. After removing the solvent from the suspension in vacuo, the residual solid was recovered and dried in an air oven at $100{ }^{\circ} \mathrm{C}$ overnight to give $1.0 \mathrm{wt} \%\left[\mathrm{Pd}(\mathrm{acac})_{2}\right] /$ porous carbon catalyst. $\left[\mathrm{Pd}(\mathrm{acac})_{2}\right] /$ SBA-15 was also prepared by the same procedure as mentioned above. All the catalysts were used without reduction pretreatment in this study.

The porous solids and Pd-supported porous solids were characterized by powder X-ray diffraction (XRD, Ultima-IV, Rigaku), nitrogen adsorption-desorption measurement (Belsorp-Mini, BEL JAPAN Inc.), and field-emission scanning electron microscopy (FE-SEM, JSM-7001F, JEOL).

Collecting the Temperature Profiles under Microwave Irradiation. All microwave irradiation experiments in this study were performed using a single-mode Discover Labmate system (2.45 GHz, CEM Corp.) using a 20-mL two-necked round-bottom flask made of Pyrex glass. Figure 1 illustrates the equipment for monitoring the temperature of the reaction mixture and testing the catalytic reactions. The flask equipped with a condenser was filled with argon, supplied from an argonfilled balloon connected to the condenser. A fiber-optic probe sensor was introduced through a rubber septum that caps the narrow-neck of the flask, immersed in the reaction mixture, and fixed at $7 \mathrm{~mm}$ from the bottom of the flask and at the horizontal center of the flask. The level of the reaction mixture (ca. $5 \mathrm{~mL}$ ) was maintained at $13 \mathrm{~mm}$ from the bottom of flask under static conditions. During the heating, the reaction mixture was carefully stirred by a magnetic stirrer bar $(14 \mathrm{~mm} \times 2 \mathrm{~mm} \phi)$, making the level of the reaction mixture slightly higher but constant. In all experiments, the microwave power was fixed at $50 \mathrm{~W}$ (not a temperature-control mode). The temperature increase of the reaction mixture was monitored by a fiberoptic probe sensor and recorded every second at a resolution of $1{ }^{\circ} \mathrm{C}$. For safety, when the temperature reached the boiling point of the solvent, the microwave power was to be automatically shut down.

The temperature-monitoring experiments under microwave irradiation at $50 \mathrm{~W}$ were performed under three different conditions as follows: (1) a solvent only; (2) a substrate or a 

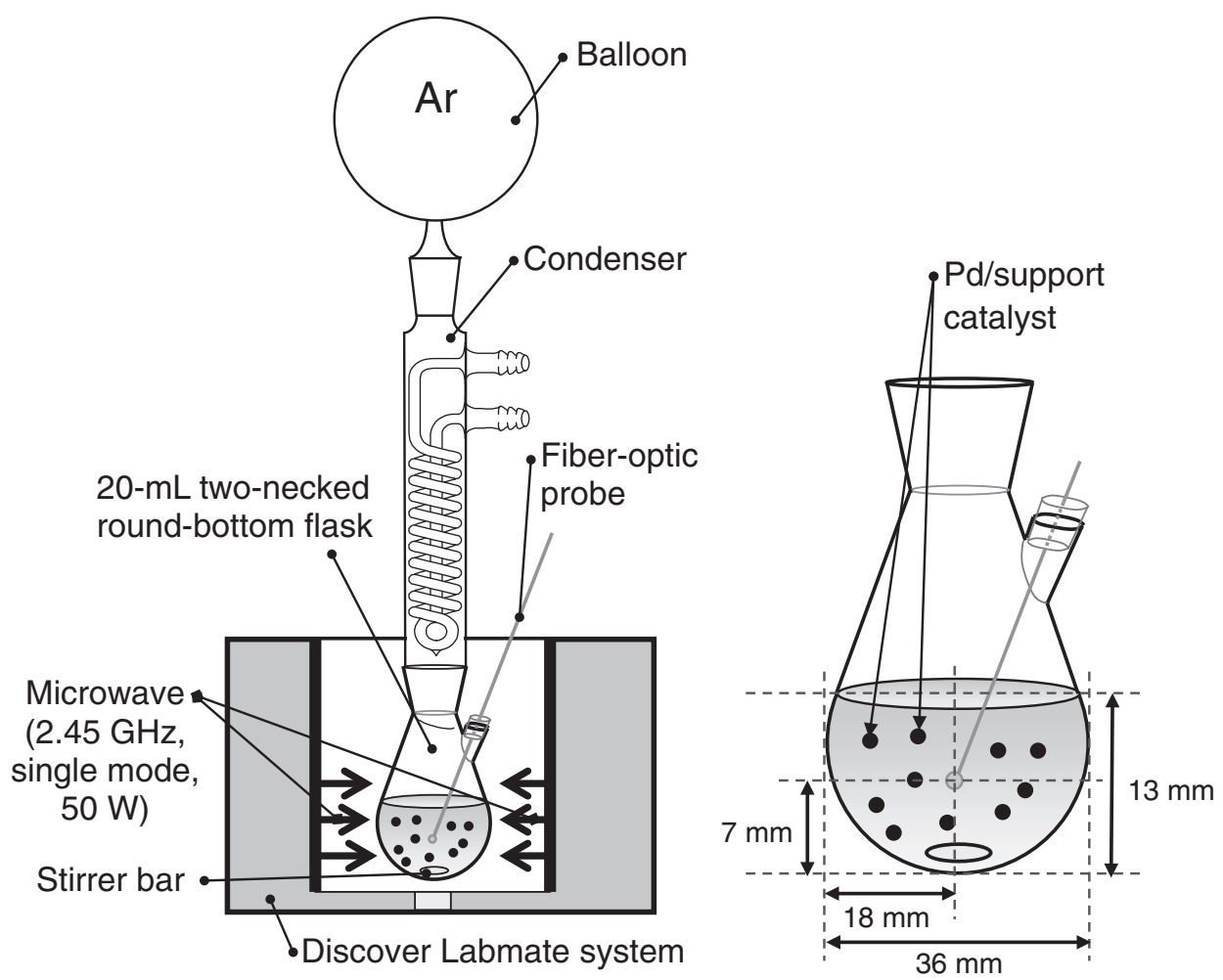

Figure 1. Schematic drawing of the equipment for the catalytic reaction under microwave radiation.

Table 1. Dielectric Properties and Boiling Points of Solvents ${ }^{\mathrm{a}}$

\begin{tabular}{llcccc}
\hline Solvent & Polarity & $\begin{array}{c}\text { Dielectric } \\
\text { constant, } \varepsilon^{\prime}\end{array}$ & $\begin{array}{c}\text { Dielectric } \\
\text { loss, } \varepsilon^{\prime \prime}\end{array}$ & tan $\delta^{\text {b) }}$ & $\begin{array}{c}\text { Boiling point } \\
/{ }^{\circ} \mathrm{C}\end{array}$ \\
\hline Ethylene glycol & polar (protic) & 37 & 49.95 & 1.35 & 198 \\
Water & polar (protic) & 80.4 & 9.889 & 0.123 & 100 \\
DMSO & polar (aprotic) & 45.0 & 37.125 & 0.825 & 153 \\
DMF & polar (aprotic) & 37.7 & 6.07 & 0.161 & 189 \\
Toluene & nonpolar & 2.4 & 0.096 & 0.040 & 111 \\
$o$-Xylene & nonpolar & 2.6 & 0.047 & 0.018 & 144 \\
cis-Decalin & nonpolar & 2.22 & - & - & 193 \\
trans-Decalin & nonpolar & 2.18 & - & - & 185 \\
\hline
\end{tabular}

a) Data from Refs. 44 and 52. b) $\tan \delta=\varepsilon^{\prime \prime} / \varepsilon^{\prime}$.

coupling product dissolved in $o$-xylene; (3) an inorganic base mixed with $o$-xylene. In category (1), several candidate solvents were chosen as listed in Table 1, which also lists the dielectric properties and boiling points. ${ }^{44,52}$ Solvent $(5 \mathrm{~mL})$ was added to the two-necked recovery flask as mentioned above, and then the microwave irradiation was performed. In category (2), the substrates and products were selected as follows: bromobenzene, 4-bromophenol, 1-bromo-4-nitrobenzene, chlorobenzene, 4-chlorophenol, and 1-chloro-4-nitrobenzene as an aryl halide component; biphenyl, 4-phenylphenol, and 4-nitrobiphenyl as a coupling product; methylboronic acid, isopropylboronic acid, and phenylboronic acid as a boronic acid component. A compound from each component $(2.5 \mathrm{mmol}$ as aryl halides, $3.75 \mathrm{mmol}$ as boronic acids, and $2.5 \mathrm{mmol}$ as coupling products) was dissolved in $o$-xylene $(5 \mathrm{~mL})$, and then the microwave irradiation was performed for $15 \mathrm{~min}$. In category (3), the selected inorganic bases were $\mathrm{Li}_{2} \mathrm{CO}_{3}$,
$\mathrm{Na}_{2} \mathrm{CO}_{3}, \mathrm{~K}_{2} \mathrm{CO}_{3}, \mathrm{LiF}, \mathrm{NaF}$, and KF. Each inorganic base $(5.0 \mathrm{mmol})$ was mixed with $o$-xylene $(5 \mathrm{~mL})$, and then the microwave irradiation was applied for $15 \mathrm{~min}$.

Suzuki-Miyaura Coupling Reaction. The Pd-catalyzed coupling reaction of 4-bromophenol with phenylboronic acid was performed under microwave or oil bath heating. First, 4-bromophenol $(2.5 \mathrm{mmol})$, phenylboronic acid $(3.75 \mathrm{mmol})$, $\mathrm{K}_{2} \mathrm{CO}_{3}(5.0 \mathrm{mmol})$, and $o$-xylene $(5.0 \mathrm{~mL})$ was added into a 20-mL two-necked round-bottom flask, and then the mixture was stirred for a few minutes under ambient atmosphere. After flushing with $\mathrm{Ar}$, an appropriate amount $(0.08 \mathrm{mmol} \% \mathrm{Pd})$ of Pd catalyst, $1.0 \mathrm{wt} \% \mathrm{Pd} / \mathrm{CMK}-3,1.0 \mathrm{wt} \% \mathrm{Pd} / \mathrm{AC}, 1.0 \mathrm{wt} \%$ $\mathrm{Pd} / \mathrm{SBA}-15$, or $\left[\mathrm{Pd}(\mathrm{acac})_{2}\right]$, was added to the reaction mixture and the reaction equipment was set up as mentioned above (Figure 1). The whole setup was introduced in the open-vessel applicator of the Discover system or immersed into a preheated oil bath. In all the experiments, the microwave power was fixed 


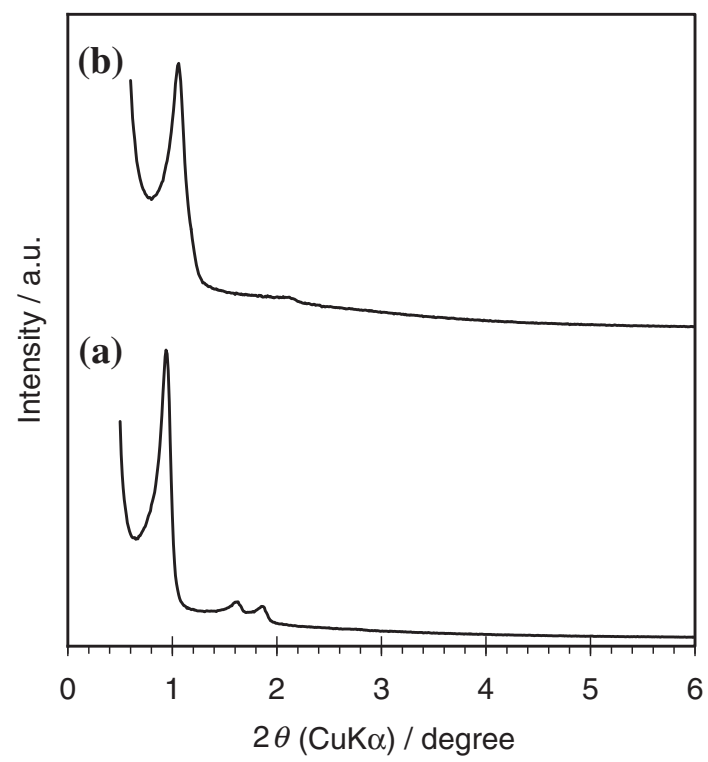

Figure 2. Powder XRD patterns of (a) SBA-15 and (b) CMK-3.

at $50 \mathrm{~W}$ (not a temperature-control mode). The reaction temperature was monitored by a fiber-optic probe sensor every second at a resolution of $1^{\circ} \mathrm{C}$.

After the reaction, the reaction mixture was rapidly cooled by immersing the whole flask in an ice bath, followed by the addition of benzene $(40 \mathrm{~mL})$ and biphenyl $(0.65 \mathrm{mmol}$ as an internal standard). The yield of the coupling product, 4-phenylphenol, was determined by gas chromatography (GC2014, Shimadzu) equipped with FID and a capillary column (DB-5MS, $50 \mathrm{~m}$ length; $0.5 \mathrm{~mm}$ i.d.; $0.25 \mu \mathrm{m}$ thickness).

\section{Results and Discussion}

Textural Properties of Catalyst Supports. Figure 2 shows the XRD patterns of SBA-15 and its carbon replica, CMK-3. Both SBA-15 and CMK-3 clearly gave 100, 110, and 200 reflection peaks originating from a $p 6 \mathrm{~mm}$ structure, indicating that CMK-3 was replicated by hexagonally ordered mesopores of SBA-15. This is also supported by FE-SEM observations of SBA-15 and CMK-3 (Figure S1). Figures 3 and 4 exhibit the nitrogen adsorption-desorption isotherms and pore size distributions of CMK-3 and activated carbon YP50F. CMK-3 gave a type-IV isotherm (Figure 3a), and showed a large BET surface area $\left(1540 \mathrm{~m}^{2} \mathrm{~g}^{-1}\right)$ and a narrow mesopore distribution at ca. $3 \mathrm{~nm}$ in diameter (Figure 4a). On the other hand, activated carbon YP50F gave a type-I isotherm (Figure 3b), and showed a large BET surface area (1610 $\mathrm{m}^{2} \mathrm{~g}^{-1}$ ) originating from disordered micropores at around $1.2 \mathrm{~nm}$ in diameter (Figure 4b). In this study, these two different types of porous carbon materials showing similar BET surface areas were used as a catalyst support. Note that Pd-modified CMK-3 (Pd/CMK-3) and Pd/AC also showed similar textural properties to those of the bare porous carbons (data not shown).

Temperature Profiles of Compounds under Microwave Irradiation. Prior to the coupling experiments, we observed the temperature histories of solvents, substrates, coupling products, and inorganic bases under microwave irradiation.

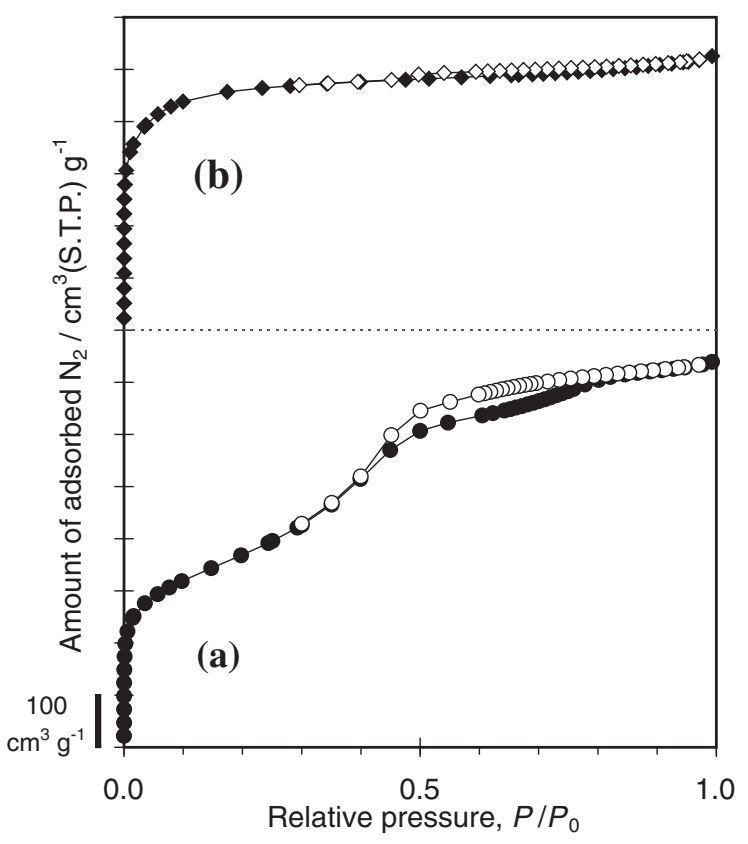

Figure 3. Nitrogen adsorption-desorption isotherms of (a) CMK-3 and (b) activated carbon YP50F. Black: adsorption branch, white: desorption branch.

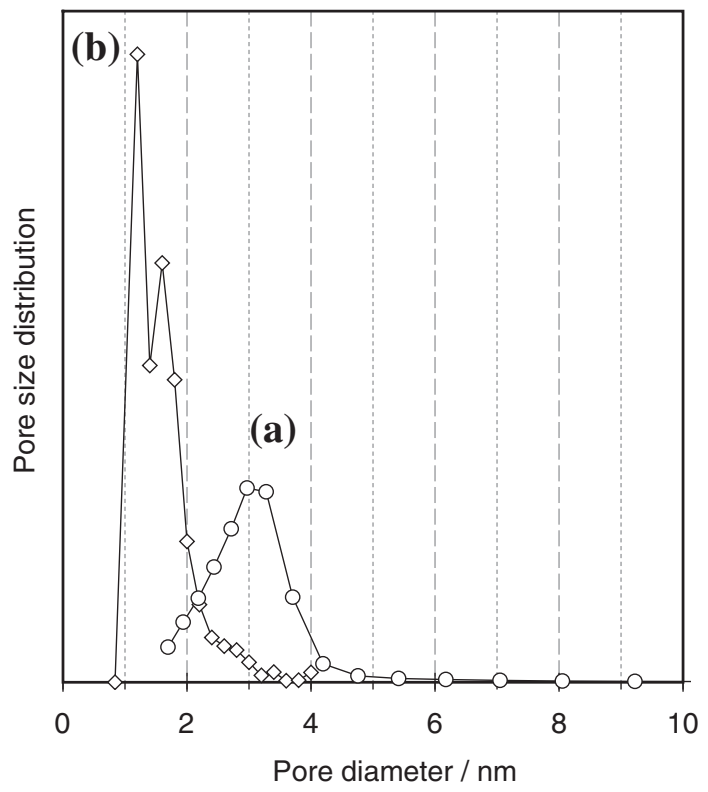

Figure 4. Pore size distributions of (a) CMK-3 and (b) activated carbon YP50F, determined by using the $\mathrm{BJH}$ and MP methods, respectively.

Figure 5 shows the time courses of temperature of each solvent $(5 \mathrm{~mL})$ under microwave irradiation at $50 \mathrm{~W}$. Polar solvents, such as ethylene glycol, water, DMSO, and DMF, showed an extremely rapid increase in temperature at ca. 40-60 ${ }^{\circ} \mathrm{C} \mathrm{min}^{-1}$, whereas nonpolar solvents, such as toluene, $o$-xylene, and decalin (cis/trans $=40 / 60$ mixture), gave a gradual slope of time versus temperature. These results are definitely in good agreement with the $\tan \delta$ values of the solvents. $o$-Xylene showed a gradual temperature increase caused by its lower $\tan \delta$, which was thus used as a common 


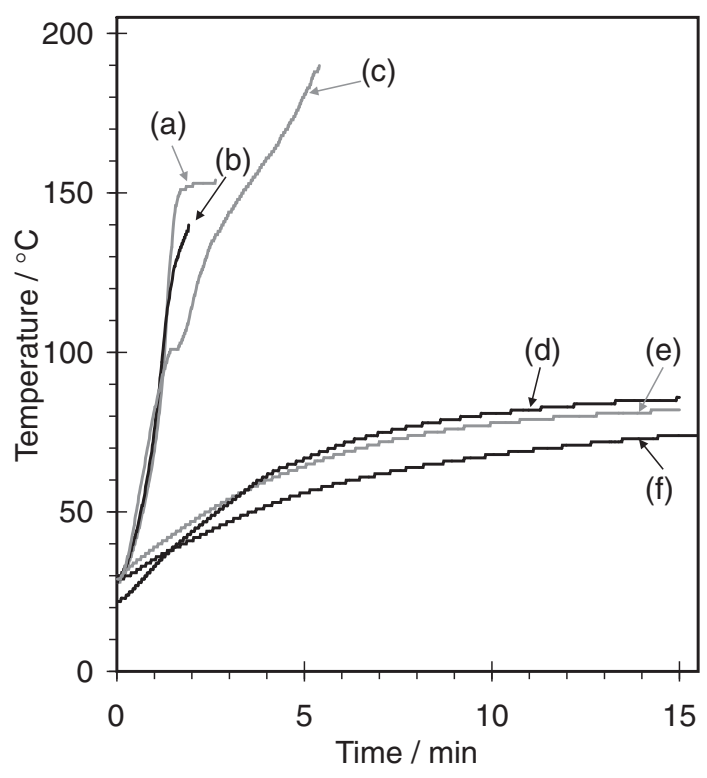

Figure 5. The time courses of temperatures of each solvent under microwave irradiation at $50 \mathrm{~W}$. (a) DMF, (b) ethylene glycol, (c) DMSO, (d) o-xylene, (e) toluene, and (f) decalin (cis/trans $=40 / 60$ mixture).

solvent throughout the investigation of the microwave heating effects of substrates, coupling products, or inorganic bases.

Table 2 summarizes the temperature of each compound mixed with $o$-xylene after $15 \mathrm{~min}$ of microwave irradiation. Phenylboronic acid was chosen as a representative boronic acid component because it showed lower temperature increase under microwave irradiation than methyl or isopropylboronic acid (Figure S2). The temperature-increases of aryl halides by microwave irradiation were in the following order: 1-bromo-4-nitrobenzene $>$ 1-chloro-4-nitrobenzene $>4$-bromophenol $>$ bromobenzene $>$ chlorobenzene $>4$-chlorophenol (Figure S3). Moreover, 4-nitrobiphenyl, possessing a nitro group, showed an extremely rapid increase in temperature, whereas irradiation of 4-phenylphenol or biphenyl resulted in a moderate increase in the temperature (Figure S4). In this study, 4-bromophenol, which showed a moderate temperature increase under microwave irradiation, was used as a common aryl halide. In inorganic bases, although six bases showed similar gradual temperature increases under microwave irradiation (Figure S5), $\mathrm{K}_{2} \mathrm{CO}_{3}$ was the most efficient base in microwaveassisted Pd-catalyzed Suzuki-Miyaura coupling (Figure S6). Therefore, our standard conditions hereafter consist of stirring a mixture of 4-bromophenol, phenylboronic acid, and $\mathrm{K}_{2} \mathrm{CO}_{3}$ in $o$-xylene or another solvent over a Pd catalyst.

The temperature profiles of the catalyst supports, CMK-3, AC, and SBA-15, were also monitored, as listed in Table 2. The carboneous materials such as CMK-3 and AC typically enhanced heating of $o$-xylene under microwave irradiation, whereas the temperature profile of mesoporous silica SBA-15 with $o$-xylene was quite similar to that of $o$-xylene only. These results imply that the carboneous materials are suitable for the catalyst support under the microwave heating.

Microwave-Assisted Suzuki-Miyaura Coupling Reaction over Pd/CMK-3 Catalyst. In this section, we describe the microwave dielectric heating effect of a carbon support on
Table 2. Temperatures of Chemical Compounds Measured by a Fiber-Optic Probe Sensor after MW Irradiation ${ }^{\text {a) }}$

\begin{tabular}{|c|c|}
\hline $\begin{array}{l}\text { Chemical compound } \\
\text { mixed with } o \text {-xylene }(5 \mathrm{~mL})\end{array}$ & $\begin{array}{l}\text { Temperature after } 15 \mathrm{~min} \\
\text { of } \mathrm{MW} \text { irradiation } /{ }^{\circ} \mathrm{C}\end{array}$ \\
\hline \multicolumn{2}{|l|}{ Solvent $(5 \mathrm{~mL})$} \\
\hline$o$-Xylene & 86 \\
\hline \multicolumn{2}{|l|}{ Boronic acid (3.75 mmol) } \\
\hline Methylboronic acid & 102 \\
\hline Isopropylboronic acid & 101 \\
\hline Phenylboronic acid & 82 \\
\hline \multicolumn{2}{|l|}{ Aryl halide $(2.5 \mathrm{mmol})$} \\
\hline 1-Bromo-4-nitrobenzene & 128 \\
\hline 1-Chloro-4-nitrobenzene & 115 \\
\hline 4-Bromophenol & 110 \\
\hline Bromobenzene & 99 \\
\hline Chlorobenzene & 98 \\
\hline 4-Chlorophenol & 74 \\
\hline \multicolumn{2}{|l|}{ Coupling product $(2.5 \mathrm{mmol})$} \\
\hline 4-Nitrobiphenyl & $133^{\mathrm{b})}$ \\
\hline 4-Phenylphenol & 95 \\
\hline Biphenyl & 87 \\
\hline \multicolumn{2}{|l|}{ Inorganic base $(5.0 \mathrm{mmol})$} \\
\hline $\mathrm{LiF}$ & 94 \\
\hline $\mathrm{Li}_{2} \mathrm{CO}_{3}$ & 93 \\
\hline $\mathrm{KF}$ & 90 \\
\hline $\mathrm{NaF}$ & 89 \\
\hline $\mathrm{K}_{2} \mathrm{CO}_{3}$ & 79 \\
\hline $\mathrm{Na}_{2} \mathrm{CO}_{3}$ & 73 \\
\hline \multicolumn{2}{|l|}{ Porous support (20 mg) } \\
\hline CMK-3 (ordered mesoporous carbon) & 116 \\
\hline AC (activated carbon, YP-50F) & 114 \\
\hline SBA-15 (ordered mesoporous silica) & 87 \\
\hline
\end{tabular}

a) MW irradiation was performed for $15 \mathrm{~min}$ under a fixed power at $50 \mathrm{~W}$. b) For $2 \mathrm{~min}$.

Suzuki-Miyaura coupling and our attempts at finding reaction conditions suitable for the Pd/CMK-3 catalyst under microwave irradiation.

Palladium complex, $\left[\mathrm{Pd}(\mathrm{acac})_{2}\right]$, loaded on various supports, e.g., CMK-3, AC, and SBA-15, and homogeneous $\left[\operatorname{Pd}(\mathrm{acac})_{2}\right]$ were tested as a catalyst for the reaction under microwave irradiation or oil bath heating, and the results are summarized in Table 3. Pd/CMK-3 gave the coupling product in the highest yield $(93.1 \%)$ under microwave irradiation (Run 1). On the other hand, the yield was only moderate $(52.1 \%)$ in the case of oil bath heating (Run 2) with the same catalyst, indicating that the irradiation of $\mathrm{Pd} / \mathrm{CMK}-3$ obviously promoted the reaction, probably due to the selective microwave heating of the carboneous body of the CMK-3 that supports $\mathrm{Pd}$ as a catalytic active site. This can be supported by the fact that when catalyzed by homogeneous $\left[\operatorname{Pd}(\mathrm{acac})_{2}\right]$ catalyst under both microwave irradiation and oil bath heating (Runs 7 and 8, respectively) the yields were lower than that in the case of heterogeneous $\mathrm{Pd} / \mathrm{CMK}-3$ catalyst. It is noteworthy that the $\mathrm{Pd} / \mathrm{CMK}-3$ promotes the coupling reaction even in $o$-xylene by microwave irradiation, although $o$-xylene is not an efficient solvent for homogeneously catalyzed coupling reactions. After 
Table 3. Catalytic Results of Suzuki-Miyaura Coupling Reaction over Various Pd Catalysts ${ }^{\text {a) }}$

\begin{tabular}{cllcc}
\hline Run & Catalyst $^{\mathrm{b})}$ & Heating ${ }^{\mathrm{c})}$ & $\begin{array}{c}\text { Yield } \\
/ \%\end{array}$ & $\begin{array}{c}\text { Temperature after } \\
\text { 4 min of reaction } /{ }^{\circ} \mathrm{C}\end{array}$ \\
\hline 1 & $1.0 \mathrm{wt} \%\left[\mathrm{Pd}(\mathrm{acac})_{2}\right] / \mathrm{CMK}-3$ & microwave & 93.1 & 112 \\
2 & $1.0 \mathrm{wt} \%\left[\mathrm{Pd}(\mathrm{acac})_{2}\right] / \mathrm{CMK}-3$ & oil bath & 52.1 & 116 \\
3 & $1.0 \mathrm{wt} \%\left[\mathrm{Pd}(\mathrm{acac})_{2}\right] / \mathrm{AC}$ & microwave & 54.4 & 122 \\
4 & $1.0 \mathrm{wt} \%\left[\mathrm{Pd}(\mathrm{acac})_{2}\right] / \mathrm{AC}$ & oil bath & 61.4 & 130 \\
5 & $1.0 \mathrm{wt} \%\left[\mathrm{Pd}(\mathrm{acac})_{2}\right] / \mathrm{SBA}-15$ & microwave & 77.8 & 112 \\
6 & $1.0 \mathrm{wt} \%\left[\mathrm{Pd}(\mathrm{acac})_{2}\right] / \mathrm{SBA}-15$ & oil bath & 95.3 & 148 \\
7 & {$\left[\mathrm{Pd}(\mathrm{acac})_{2}\right]$} & microwave & 41.9 & 78 \\
8 & {$\left[\operatorname{Pd}(\mathrm{acac})_{2}\right]$} & oil bath & 29.9 & 143 \\
\hline
\end{tabular}

a) Reaction conditions: 4-bromophenol, $2.5 \mathrm{mmol}$; phenylboronic acid, $3.75 \mathrm{mmol} ; \mathrm{K}_{2} \mathrm{CO}_{3}, 5.0 \mathrm{mmol} ; o$-xylene, $5.0 \mathrm{~mL}$. b) $0.08 \mathrm{mmol} \%$ Pd. c) Microwave irradiation was performed under fixed power at $50 \mathrm{~W}$; oil bath heating was performed by immersing the flask into a preheated oil bath at $140{ }^{\circ} \mathrm{C}$.

Table 4. Catalytic Results of Suzuki-Miyaura Coupling Reaction in Various Solvents ${ }^{\text {a) }}$

\begin{tabular}{|c|c|c|c|c|c|}
\hline Solvent & $\begin{array}{l}\text { Halving depth of } \\
\text { power, } L^{\mathrm{b})} / \mathrm{cm}\end{array}$ & Catalyst $^{\mathrm{c})}$ & Heating $\left.{ }^{d}\right)$ & $\begin{array}{l}\text { Yield } \\
/ \%\end{array}$ & $\begin{array}{l}\text { Temperature after } \\
4 \text { min of reaction } /{ }^{\circ} \mathrm{C}\end{array}$ \\
\hline \multirow[t]{2}{*}{$o$-Xylene } & 65.8 & $\mathrm{Pd} / \mathrm{CMK}-3$ & microwave & 93.1 & 127 \\
\hline & & & oil bath & 52.1 & 116 \\
\hline \multirow[t]{2}{*}{ Toluene } & 30.8 & $\mathrm{Pd} / \mathrm{CMK}-3$ & microwave & 37.0 & 107 \\
\hline & & & oil bath & 48.5 & 111 \\
\hline \multirow[t]{2}{*}{ DMF } & 1.93 & $\mathrm{Pd} / \mathrm{CMK}-3$ & microwave & 21.5 & 151 \\
\hline & & & oil bath & 50.6 & 146 \\
\hline \multirow[t]{2}{*}{ DMSO } & 0.35 & $\mathrm{Pd} / \mathrm{CMK}-3$ & microwave & 30.5 & 183 \\
\hline & & & oil bath & 44.4 & 188 \\
\hline
\end{tabular}

a) Reaction conditions: 4-bromophenol, $2.5 \mathrm{mmol}$; phenylboronic acid, $3.75 \mathrm{mmol} ; \mathrm{K}_{2} \mathrm{CO}_{3}, 5.0 \mathrm{mmol}$; solvent, $5.0 \mathrm{~mL}$. b) The halving depth of power, $L$, is expressed as the equation, $L=\lambda /\left(2 \pi \varepsilon^{\prime 1 / 2} \tan \delta\right)$, where $\lambda$ is wavelength $(0.12 \mathrm{~m}$ at $2.45 \mathrm{GHz}), \varepsilon^{\prime}$ is the dielectric constant of the solvent, and $\tan \delta$ is the loss factor of the solvent. c) $0.08 \mathrm{mmol} \% \mathrm{Pd}$. d) Microwave irradiation was performed under fixed power at $50 \mathrm{~W}$; oil bath heating was performed by immersing the flask into a preheated oil bath at $190^{\circ} \mathrm{C}$.

4-min irradiation, the temperature of the $\left[\mathrm{Pd}(\mathrm{acac})_{2}\right]$-catalyzed reaction mixture (Run 7) was as low as $78^{\circ} \mathrm{C}$, whereas the corresponding temperature of $\mathrm{Pd} / \mathrm{CMK}-3$-catalyzed reaction mixture (Run 1) reached $112^{\circ} \mathrm{C}$, again indicating that $\mathrm{CMK}-3$ efficiently absorbs microwave energy, converts it to heat, and heats up the Pd active sites.

The yield of the coupling product over Pd/SBA-15 catalyst by microwave irradiation (Run 5) was moderate (77.8\%) but obviously lower than that over Pd/CMK-3. Such a lower yield is probably caused by less microwave absorptivity of the allsilica material SBA-15, as confirmed by a gradual temperatureincrease under microwave irradiation by using Pd/SBA-15, as compared to Pd/CMK-3 (Figure S7). The reaction catalyzed by $\mathrm{Pd} / \mathrm{AC}$ under microwave irradiation (Run 3) gave the product in relatively low yield $(54.4 \%)$ similar to the yield when catalyzed by Pd/AC under oil bath heating (Run 4, $61.4 \%$ ). A temperature-increase of the Pd/CMK-3 system under microwave irradiation was comparable to that by using $\mathrm{Pd} / \mathrm{AC}$ (Figure S7), due to the similar microwave absorptivity of CMK-3 and $\mathrm{AC}$, both of which are carboneous materials. On the other hand, the yield by using Pd/CMK-3 was higher than that by using $\mathrm{Pd} / \mathrm{AC}$ because of a high dispersion of $\mathrm{Pd}$ on the internal surface of CMK-3 and a high accessibility of substrate molecules to Pd within its uniform mesopores.

These findings suggest that CMK-3 is an efficient catalyst support in the microwave-assisted Pd-catalyzed coupling reaction in $o$-xylene with a low $\tan \delta$ value. In other words, CMK-3 provides a "carbon nanoflask," giving a specific reaction field that consists of (1) uniform mesopores several nanometers in diameter, (2) a spacious surface immobilizing inorganic/organic catalysts, and (3) carboneous walls with a high microwave absorptivity, making it possible to selectively heat the chemicals existing in the ordered mesopores, especially immobilized catalyst and reactant molecules, and efficiently promotes the catalytic reactions in there.

Effect of Microwave Absorptivity of Solvent on Pd/ CMK-3-Catalyzed Coupling Reaction. We have also investigated the effect of microwave absorptivity of solvent on the Suzuki-Miyaura coupling reactions under microwave irradiation. Toluene, DMSO, or DMF was used as a solvent instead of $o$-xylene, and the catalytic results over $\mathrm{Pd} / \mathrm{CMK}-3$ are summarized in Table 4.

The use of much less polar solvent such as $o$-xylene or toluene gave the coupling product in a higher yield in the microwave-assisted $\mathrm{Pd} / \mathrm{CMK}$-3-catalyzed reaction, in comparison with the use of polar solvent such as DMF or DMSO. Figure 6 shows the time courses of the reaction temperature using various solvents in the $\mathrm{Pd} / \mathrm{CMK}$-3-catalyzed coupling reaction under microwave irradiation. The temperature of the reaction mixture in DMSO or DMF reached in $1.5 \mathrm{~min} 185$ or $150^{\circ} \mathrm{C}$, respectively, near the boiling temperature (189 or $154^{\circ} \mathrm{C}$, respectively), ascribable to their high microwave 


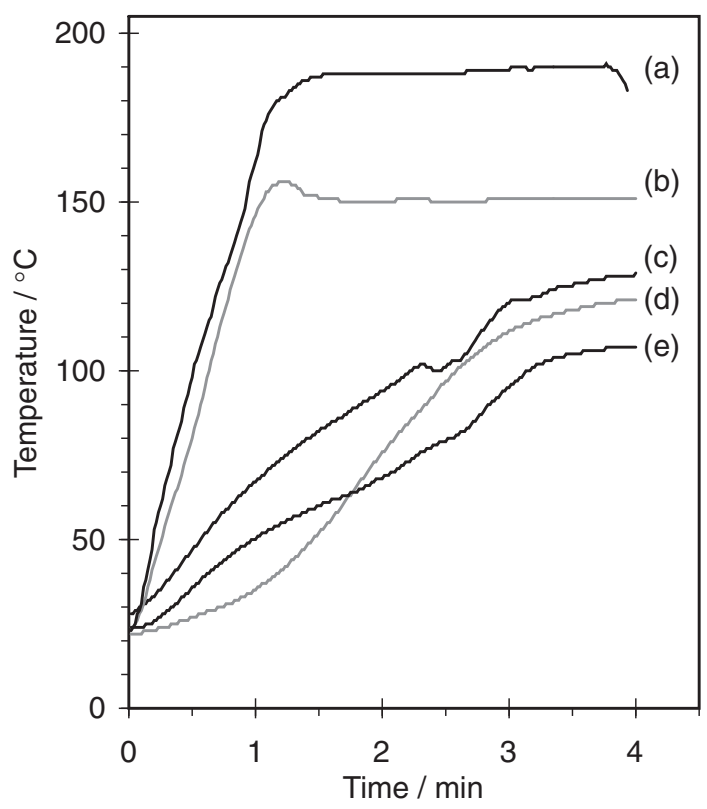

Figure 6. The time courses of the reaction temperature catalyzed by $\mathrm{Pd} / \mathrm{CMK}-3$ under microwave irradiation in various solvents such as (a) DMSO, (b) DMF, (c) $o$-xylene, (d) decalin (cis/trans $=40 / 60$ mixture), or (e) toluene.

absorptivity confirmed by high $\tan \delta$ values. In contrast, in the nonpolar or much less polar solvents (o-xylene, decalin, or toluene), a gradual increase in the reaction temperature was observed. These results imply that CMK-3 in a nonpolar solvent is selectively heated by microwave irradiation, whereas microwave dielectric heating of solvent predominantly occurs in polar solvents and CMK-3 is heated by heat transfer from the preheated solvent. This explains that the use of nonpolar solvent results in the higher product yield in the microwaveassisted $\mathrm{Pd} / \mathrm{CMK}$-3-catalyzed reactions.

It is interesting to discuss the microwave dielectric heating of solvent considering the halving depth of microwave power. The halving depth of power, $L$, is expressed as the equation, $L=\lambda /\left(2 \pi \varepsilon^{\prime 1 / 2} \tan \delta\right)$, where $\lambda$ is the wavelength of a microwave $(12.2 \mathrm{~cm}$ at $2.45 \mathrm{GHz}), \varepsilon^{\prime}$ is the dielectric constant of a solvent, $\tan \delta$ is the loss factor of a solvent, ${ }^{53}$ and the $L$ values of various solvents used in this study are listed in Table 4. The 2.45-GHz microwave oscillated from the Discover system horizontally comes to the flask with a $3.7 \mathrm{~cm}$ horizontal diameter. Since $o$-xylene $(L=65.8 \mathrm{~cm})$ in the flask would hardly absorb the microwave power, the power would be efficiently conducted to the $\mathrm{Pd} / \mathrm{CMK}-3$ dispersed in $o$-xylene in the flask. On the other hand, DMF $(L=1.93 \mathrm{~cm})$ or DMSO $(L=0.35 \mathrm{~cm})$ conspicuously absorbs the microwave energy, causing predominant heating of the solvent that hinders the transmission of microwave to Pd/CMK-3.

Comparing oil bath heating with microwave irradiation to Pd/CMK-3-catalyzed coupling reaction, the microwave dielectric heating effects are clearly observed. In the case of oil bath heating of the reaction mixture with $\mathrm{Pd} / \mathrm{CMK}-3$, each of four solvents used in this study showed a similar temperature increase that includes rapid heating to each boiling temperature, as shown in Figure 7. Regardless of the polarity of solvent, the

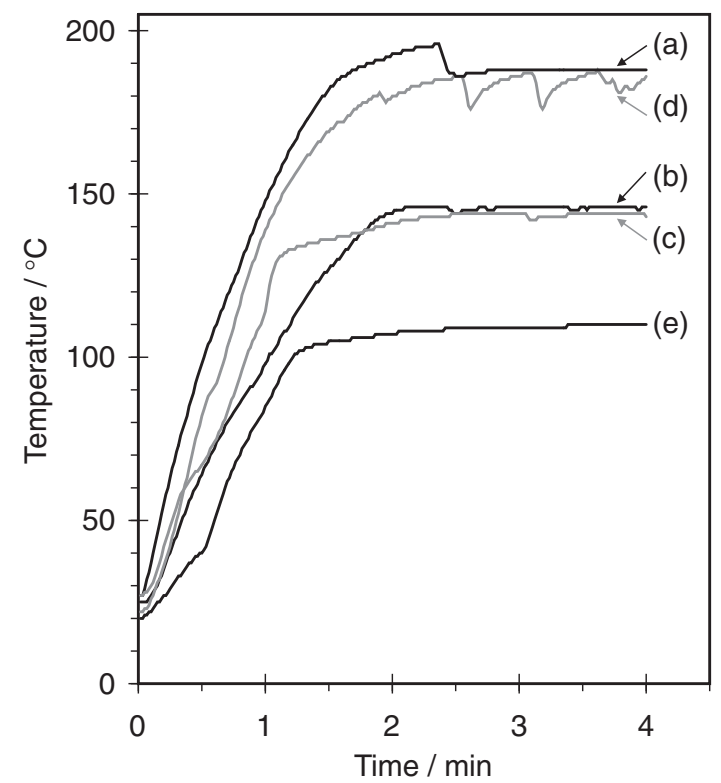

Figure 7. The time courses of the reaction temperature catalyzed by $\mathrm{Pd} / \mathrm{CMK}-3$ under oil bath heating in various solvents such as (a) DMSO, (b) DMF, (c) o-xylene, (d) decalin (cis/trans $=40 / 60$ mixture), or (e) toluene.

yields of the coupling products under oil bath heating were around $45-50 \%$ in common. Under microwave irradiation, the reaction in $o$-xylene, which is a nonpolar solvent, gave the product in much higher yield $(93.1 \%)$, in comparison with oil bath heating $(52.1 \%)$. In contrast, the microwave heating was less effective than the oil bath heating in DMF or DMSO, a typical aprotic, polar solvent (Table 4).

These results indicate that nonpolar solvents with lower $\tan \delta$ value, especially $o$-xylene, accentuate the microwave dielectric heating effect of "carbon nanoflask" CMK-3 as a catalyst support, leading to the acceleration of the Pd-catalyzed coupling reaction by microwave irradiation.

\section{Conclusion}

The microwave dielectric heating effects of reactants, solvents, and catalyst supports on the temperature of the reaction mixture and the product yield in the Suzuki-Miyaura coupling reaction under microwave irradiation have been investigated. $\mathrm{Pd} / \mathrm{CMK}-3$ was the most effective catalyst in the microwave-assisted coupling reaction in nonpolar solvent, in particular, $o$-xylene with a lower $\tan \delta$ value efficiently enhanced the reaction. The current reaction system could be considered a "carbon nanoflask" system, supported by the fact that CMK-3 in $o$-xylene under microwave irradiation gives a specific reaction field consisting of carboneous walls with an extremely spacious surface and high microwave absorptivity, making it possible to selectively heat the chemicals existing in the ordered mesopores.

This work was partly supported by New Energy and Industrial Technology Development Organization (NEDO) to Y. K. We thank Prof. Y. Wada of Tokyo Institute of Technology and Dr. J. Sugiyama of AIST for fruitful discussions and valuable comments. 


\section{Supporting Information}

Figure S1 shows typical FE-SEM images of SBA-15 and CMK-3. Figures S2-S5 show the time-courses of temperatures of the mixture with $o$-xylene by microwave heating. Figure S6 shows the product yield and the time-courses of the reaction temperatures of the coupling reaction catalyzed by Pd/CMK-3. Figure $\mathrm{S} 7$ shows the time-courses of the reaction temperatures catalyzed by Pd/CMK-3, Pd/AC, or Pd/SBA-15. This material is available free of charge on the web at http://www.csj.jp/ journals/bcsj/.

\section{References}

1 R. J. Farrauto, C. H. Bartholomew, Fundamental of Industrial Catalytic Process, Blackie Academic and Professional, New York, 1997.

2 N. Miyaura, K. Yamada, A. Suzuki, Tetrahedron Lett. 1979, $20,3437$.

3 N. Miyaura, A. Suzuki, J. Chem. Soc., Chem. Commun. 1979, 866.

4 G. Marck, A. Villiger, R. Buchecker, Tetrahedron Lett. 1994, 35, 3277.

5 C. R. LeBlond, A. T. Andrews, Y. Sun, J. R. Sowa, Jr., Org. Lett. 2001, 3, 1555.

6 D. S. Ennis, J. McManus, W. Wood-Kaczmar, J. Richardson, G. Smith, A. Carstairs, Org. Process Res. Dev. 1999, 3, 248.

7 M. T. Reetz, R. Breinbauer, K. Wanninger, Tetrahedron Lett. 1996, 37, 4499.

8 R. G. Heidenreich, K. Köhler, J. G. E. Krauter, J. Pietsch, Synlett 2002, 1118.

9 T. Tagata, M. Nishida, J. Org. Chem. 2003, 68, 9412.

10 A. Arcadi, G. Cerichelli, M. Chiarini, M. Correa, D. Zorzan, Eur. J. Org. Chem. 2003, 4080.

11 D. A. Conlon, B. Pipik, S. Ferdinand, C. R. LeBlond, J. R. Sowa, Jr., B. Izzo, P. Collins, G.-J. Ho, M. Williams, Y.-J. Shi, Y. Sun, Adv. Synth. Catal. 2003, 345, 931.

12 F.-X. Felpin, T. Ayad, S. Mitra, Eur. J. Org. Chem. 2006, 2679.

13 L. Yin, J. Liebscher, Chem. Rev. 2007, 107, 133.

14 A. Molnár, Chem. Rev. 2011, 111, 2251.

15 H. Lysén, K. Köhler, Synlett 2005, 1677.

16 D. Kudo, Y. Masui, M. Onaka, Chem. Lett. 2007, 36, 918.

17 K. Okumura, H. Matsui, T. Sanada, M. Arao, T. Honma, S. Hirayama, M. Niwa, J. Catal. 2009, 265, 89.

18 K. Okumura, H. Matsui, T. Tomiyama, T. Sanada, T. Honma, S. Hirayama, M. Niwa, ChemPhysChem 2009, 10, 3265.

19 S. P. Andrews, A. F. Stepan, H. Tanaka, S. V. Ley, M. D. Smith, Adv. Synth. Catal. 2005, 347, 647.

20 K. Mori, T. Hara, M. Oshiba, T. Mizugaki, K. Ebitani, K. Kaneda, New J. Chem. 2005, 29, 1174.

21 R. Gedye, F. Smith, K. Westaway, H. Ali, L. Baldisera, L. Laberge, J. Rousell, Tetrahedron Lett. 1986, 27, 279.
22 R. J. Giguere, T. L. Bray, S. M. Duncan, G. Majetich, Tetrahedron Lett. 1986, 27, 4945.

23 C. O. Kappe, Angew. Chem., Int. Ed. 2004, 43, 6250.

24 N. E. Leadbeater, Chem. Commun. 2005, 2881.

25 M. Larhed, A. Hallberg, J. Org. Chem. 1996, 61, 9582.

26 V. V. Namboodiri, R. S. Varma, Green Chem. 2001, 3, 146.

27 L. Bai, J.-X. Wang, Y. Zhang, Green Chem. 2003, 5, 615.

28 N. E. Leadbeater, M. Marco, Angew. Chem., Int. Ed. 2003, 42,1407

29 R. K. Arvela, N. E. Leadbeater, M. S. Sangi, V. A. Williams, P. Granados, R. D. Singer, J. Org. Chem. 2005, 70, 161.

30 G. Miao, P. Ye, L. Yu, J. Org. Chem. 2005, 70, 2332.

31 N. E. Leadbeater, M. Marco, Org. Lett. 2002, 4, 2973.

32 N. E. Leadbeater, M. Marco, J. Org. Chem. 2003, 68, 888.

33 C. Nájera, J. Gil-Moltó, S. Karlström, Adv. Synth. Catal. 2004, 346, 1798.

34 O. Navarro, H. Kaur, P. Mahjoor, S. P. Nolan, J. Org. Chem. 2004, 69, 3173.

35 G. W. Kabalka, R. M. Pagni, L. Wang, V. Namboodiri, C. M. Hair, Green Chem. 2000, 2, 120.

36 J.-X. Wang, Y. Yang, B. Wei, Y. Hu, Y. Fu, Bull. Chem. Soc. Jpn. 2002, 75, 1381.

37 R. K. Arvela, N. E. Leadbeater, Org. Lett. 2005, 7, 2101.

38 I. R. Baxendale, C. M. Griffiths-Jones, S. V. Ley, G. K. Tranmer, Chem.-Eur. J. 2006, 12, 4407.

39 Z. Zheng, H. Li, T. Liu, R. Cao, J. Catal. 2010, 270, 268.

40 M. Yasuda, T. Somyo, A. Baba, Angew. Chem., Int. Ed. 2006, 45, 793 .

41 S. A. Babu, M. Yasuda, Y. Tsukahara, T. Yamauchi, Y. Wada, A. Baba, Synthesis 2008, 1717.

42 M. A. Herrero, J. M. Kremsner, C. O. Kappe, J. Org. Chem. 2008, 73, 36.

43 C. Gabriel, S. Gabriel, E. H. Grant, B. S. J. Halstead, D. M. P. Mingos, Chem. Soc. Rev. 1998, 27, 213.

44 B. L. Hayes, Microwave Synthesis: Chemistry at the Speed of Light, CEM Publishing, Matthews NC, 2002.

45 Y. Tsukahara, A. Higashi, T. Yamauchi, T. Nakamura, M. Yasuda, A. Baba, Y. Wada, J. Phys. Chem. C 2010, 114, 8965.

46 B. K. Banik, K. J. Barakat, D. R. Wagle, M. S. Manhas,

A. K. Bose, J. Org. Chem. 1999, 64, 5746.

47 J. F. Quinn, D. A. Razzano, K. C. Golden, B. T. Gregg, Tetrahedron Lett. 2008, 49, 6137.

48 Y.-M. Ma, X.-Y. Wei, X. Zhou, K.-Y. Cai, Y.-L. Peng, R.-L. Xie, Y. Zong, Y.-B. Wei, Z.-M. Zong, Energy Fuels 2009, 23, 638. 49 Y. Wada, H. Yin, T. Kitamura, S. Yanagida, Chem. Lett. 2000, 632.

50 S. Jun, S. H. Joo, R. Ryoo, M. Kruk, M. Jaroniec, Z. Liu, T. Ohsuna, O. Terasaki, J. Am. Chem. Soc. 2000, 122, 10712.

51 J. S. Lee, S. H. Joo, R. Ryoo, J. Am. Chem. Soc. 2002, 124, 1156.

52 W. F. Seyer, G. M. Barrow, J. Am. Chem. Soc. 1948, 70, 802.

53 A. R. von Hippel, Dielectric Materials and Application, The MIT Press, 1966. 